\title{
CROUZON SYNDROME - CLINICAL-EVOLUTIVE PARTICULARITIES. CASE REPORT
}

\author{
Aniko Maria Manea ${ }^{1,2}$, Nicoleta Kiritescu ${ }^{2}$, Dobre Mihaela ${ }^{2}$, Mariana Boia ${ }^{1,2}$ \\ I"Victor Babes" University of Medicine and Pharmacy Timisoara, Romania \\ 2"Louis Turcanu” Children's Emergency Hospital Timisoara, Romania
}

\begin{abstract}
The Crouzon's Syndrome is a rare genetic disorder, with an incidence between $1 / 25,000$ to $1 / 100,000$ newborn babies, transmitted autosomal dominant, characterized by facial dysmorphism and craniosynostosis, based on those characteristic can be diagnosed early. We present the case of a premature newborn female admitted to the Hospital Division of Neonatology "Louis Țurcanu" with facial dysmorphism. The anamnestic investigation revealed that the patient's mother and sister suffer from the same type of affection. The patients affected by Crouzon Syndrome have a normal lifespan, and $97 \%$ of them have a normal intelligence. The quality of their life is affected by aesthetic considerations and the severity of abnormalities they present.
\end{abstract}

Keywords: Crouzon's Syndrome, FGFR2 gene, craniosinostosys

\section{INTRODUCTION}

Crouzon syndrome is a genetic disease characterized by craniosynostosis, frequently set during the intrauterin life or in the first years of life. The prevalence is estimated between $1 / 25,000-1 / 100,000$ newborn infants. The genetic cause is represented by the mutation of the genes: FGFR2 ((fibroblast growth factor receptor 2) (95\% of cases) sau FGFR3 (fibroblast growth factor receptor 3) (5\% of cases).

The condition is autosomal dominant transmitted, with reduced variability (1). Approximately $40 \%$ of reported cases do not have family history of Crouzon Syndrome, known as "de novo" mutations. In $60 \%$ of tested patients is found a mutation of the gene FGFR2 (fibroblast growth factor receptor 2) on the chromosome $10 \mathrm{q} 26$. FGFR is the receptor of fibroblastic growth, a protein that controls a growth of fibroblast.

Prenatal diagnosis is possible by identifying the mutations of the genes through the chorionic villi in the 10th week of pregnancy, or through the analysis of the fetal cells from the amniotic fluid in the 16 th week of pregnancy $(4,7)$.

\section{CASE REPORT}

We are presenting the case of premature newborn female (gestational age - 32 week, birth weight 1,600 grams) with emphasized dysmorphism, clinical data along with history data and biological data guides us towards the diagnosis of Crouzon syndrome, a rare condition found in the pediatric medical practice.

Family history data shows that both the mom and the sister (been prematurely admitted to our clinic, now aged 2 years and 6 months) have the same affection, have the same condition which leads us to a comprehensive range of laboratory investigations.

Clinical exam highlights accentuated dysmorphism, hypertelorism, fissure vents facing down, low-set ears, enlarged nasal bone, retrognathism, inferior jaw hypoplasia, jaundice, palate ogive, Simian right hand fold, long and thin fingers, "sandal gap", legs edema; thorax with sunk stern, intercostal and subcostal retraction, increased respiratory rate, $\mathrm{SaO}_{2}$ 95-98\% with oxygenotherapy. Hypotonia diminished archaic reflexes. Stradded cranial sutures. 


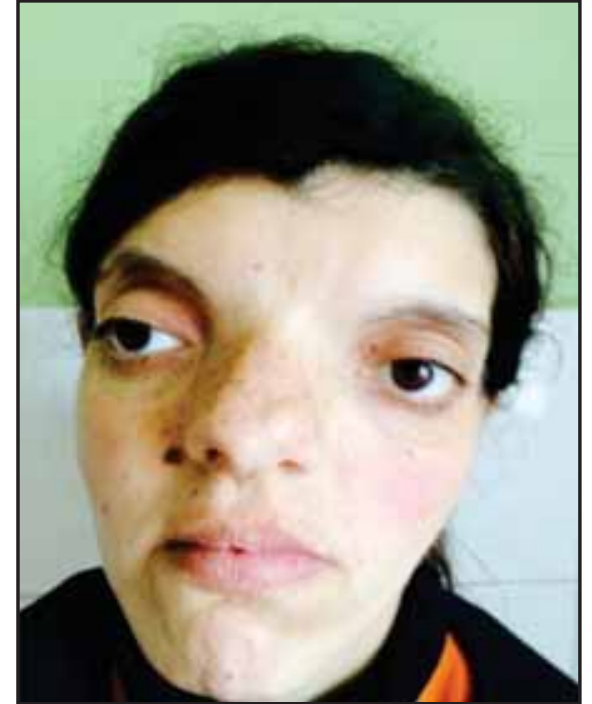

Mother

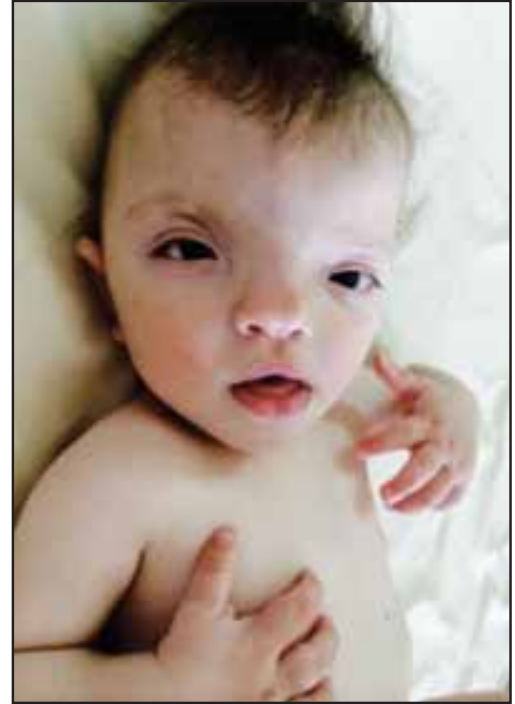

Sister

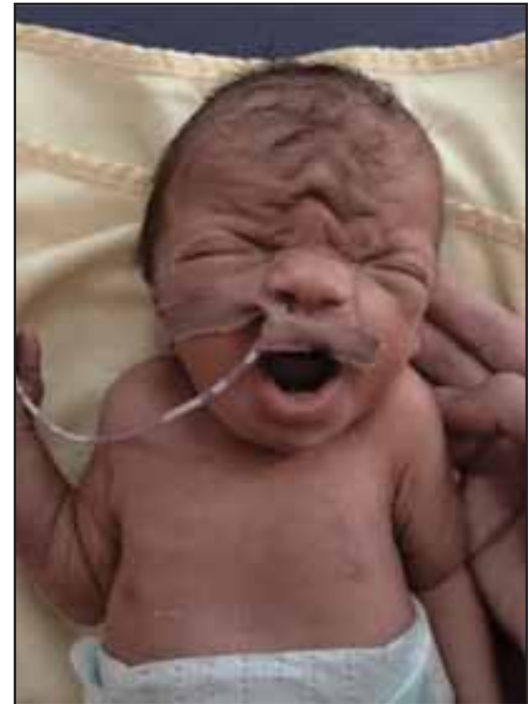

Patient

\section{FIGURE 1}

For positive diagnosis and diagnostic potential associated comorbidities was performed: transfontanelar ultrasound (Fig. 1) which reveals partial agenesis of the corpus callosum and mild periventricular leukomalacia, as well as bone radiographs (Fig. 2) with normal appearance.
Ophtalmologic examination shows just a retinopathy of prematurity.

Particular phenotype raises suspicion on the Crouzon syndrome because of why genetic examination it is requested and blood samples are colected for molecular analysis and elucidate the diagnosis.
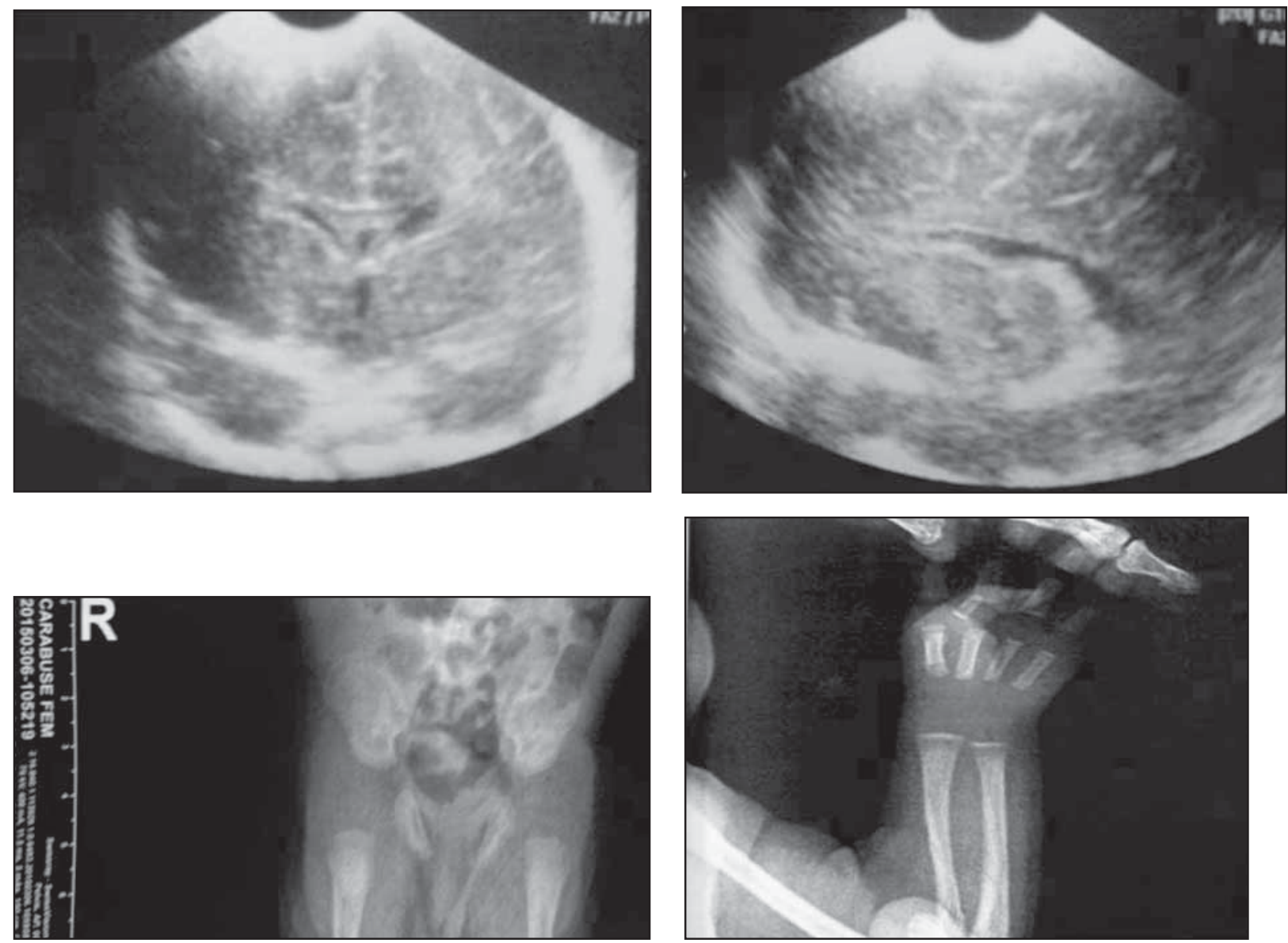

FIGURE 2. Transfontanelar ultrasound and bone radiography 
During the hospitalization, under the established treatment, the evolution was favorable. Evaluated through the follow-up programe, after the multidisciplinary consults effectuated, the diagnosis of severe psychomotor retardation needing multiple healthcare, kinetotherapy and psychomotor recovery.

\section{DISCUSSIONS}

Early suture of the cranial bones even from the intrauterin life, determines in evolution microcephaly with pronounced psychomotor retardation $(4,5)$.

Because of the abnormal position of the eyeballs and the very small depth of the orbits, aswell as the high intracranial pressure, visual disturbances are common (3). Untreated intracranial hypotension determines, in time, the atrophy of the optical nerve. Because craniostenosis can have a late debute in bigger children, can go easily undiagnosed. The only symptome is the headache because of the increased intracranial pressure. Therefore patients with Crouzon syndrome must be periodically evaluated for signs and symptoms of hydrocephalus. $(7,8)$

Patients with Crouzon syndrome can present narrowed auditory canals which leads to transmission hearing loss - periodical monitoring of the auditory functions is necessary, some of the patients require prosthetic hearing from very young ages $(9,11)$.
Patients with Crouzon syndrome have a normal life expectancy, $97 \%$ of them having normal inteligence. Life quality is affected by aesthetic considerations and depends on the severity of the present abnormalities of the patients. The syndrome cannot be treated but the life quality can be improved. Treatment is individualized and is specific to present abnormalities. Morbidity and mortality are low when the medical attention for the patient is followed.

\section{CONCLUSIONS}

Even the Crouzon Syndrome is a rare affection in medical pediatric practice, and is extremely rare associated with prematurity, in our case both the patient and her sister were born premature.

At the present case the percentage of modified gene transmission is $100 \%$, even it is a disease with autosomal dominant transmission, the descendants of a person having a $50 \%$ risk of inheriting the modified gene from its parent.

The CS diagnosis within the family was established at first birth, the mother not knowing to have this affection until then; although she was advised, in our clinic, about the risk of transmitting the affection to the next birth and about the importance of periodic controls, the second birth was not kept under control and the CS diagnosis was established postnatal.

\section{REFERENCES}

1. Fogh-Andersen P. Craniofacial dysostosis (Crouzon's disease) as a dominant hereditary affection. Nord Med. 1943; 18:993-996

2. Crouzon L.E. Dysostose cranio-faciale héréditaire. Bulletin de la Société des Médecins des Hôpitaux de Paris. 1912; 33:545-555

3. Fries P.D., Katowitz J.A. Congenital craniofacial anomalies of ophthalmic importance. Surv Ophthalmol. 1990; 35:87-119

4. Hlongwa P. Early orthodontic management of Crouzon Syndrome: A case report. J Maxillofac Oral Surg. 2009; 8:74-76

5. Jarund M., Lauritzen C. Craniofacial dysostosis: Airway obstruction and craniofacial surgery. Scand J Plast Reconstr Surg Hand Surg. 1996; 30:275-279

6. Rollnick B.R. Germinal mosaicism in Crouzon syndrome. Clin. Genet. 1988; 33: 145-150

7. Reardon W., Winter R.M., Rutland P., Pulleyn L.J., Jones B.M., Malcolm S. Mutations in the fibroblast growth factor receptor 2 gene cause Crouzon syndrome. Nature Genet. 1994; 8: 98-103

8. Dodge H.W., Wood M.W., Kennedy R.L.J. Craniofacial dysostosis: Crouzon's disease. Pediatrics. 1959; 23: 98-106

9. Pinkerton O.D., Pinkerton F.J. Hereditary craniofacial dysplasia. Am. J. Ophthal. 1952; 35: 500-506

10. Meyers G.A., Orlow S.J., Munro I.R., et al. Fibroblast growth factor receptor 3 (FGFR3) transmembrane mutation in Crouzon syndrome with acanthosis nigricans. Nature Genet. 1995; 11: 462-464

11. Juberg R.C., Chambers S.R. An autosomal recessive form of craniofacial dysostosis (the Crouzon syndrome). J. Med. Genet. 1973; 10: $89-93$ 